\title{
Middle East Respiratory Syndrome Coronavirus and Severe Acute Respiratory Syndrome Coronavirus
}

\author{
Jaffar A. Al-Tawfiq, MD, FRCPL, FACP, FRCPE ${ }^{1,2,3}$ \\ 1 Johns Hopkins Aramco Healthcare, Dhahran, Saudi Arabia \\ 2 Infectious Disease Division, Department of Medicine, Indiana \\ University School of Medicine, Indianapolis, Indiana \\ 3 Infectious Disease Division, Department of Medicine, Johns Hopkins \\ University School of Medicine, Baltimore, Maryland \\ ${ }^{4}$ Director Research \& Innovation Center, Research Center \\ Department, King Saud Medical City, Ministry of Health, Riyadh, \\ Saudi Arabia \\ ${ }^{5}$ Department of Medicine, Al-Faisal University, Riyadh, Saudi Arabia \\ ${ }^{6}$ Hubert Department of Global Health, Rollins School of Public Health, \\ Emory University, Atlanta, Georgia
}

Ziad A. Memish, MD, FRCPC, FACP, FRCPE, FRCPL, FPH $4,5,6$

\begin{abstract}
Address for correspondence Ziad A. Memish, MD, FRCPC, FACP, FRCPE, FRCPL, FPH, Department of Medicine, Al-Faisal University, PO Box 54146, Riyadh 11514, Saudi Arabia (e-mail: zmemish@yahoo.com).
\end{abstract}

Semin Respir Crit Care Med 2020;41:568-578.

\author{
Abstract \\ Keywords \\ - MERS \\ - Middle East \\ respiratory syndrome \\ coronavirus \\ - epidemiology \\ - control measures \\ - transmission \\ - Saudi Arabia
}

Emerging infectious diseases continue to be of a significant importance worldwide with the potential to cause major outbreaks and global pandemics. In 2002, the world had witnessed the appearance of the severe acute respiratory syndrome coronavirus in China which disappeared abruptly within 6 months. About a decade later, a new and emerging novel coronavirus named the Middle East respiratory syndrome coronavirus (MERS-CoV) was described in a patient from Saudi Arabia. These two coronaviruses shared multiple similarities in the epidemiology, clinical presentations, and posed challenges in its prevention and management. Seven years since its discovery, MERS-CoV continues to be a lethal zoonotic pathogen capable of causing severe pneumonia with high case fatality rates and the ability to cause large health care-associated outbreaks.
Emerging infectious diseases continue to be of a significant importance worldwide with the potential to cause major outbreaks and global pandemics. In 2002, the world had witnessed the appearance of the severe acute respiratory syndrome coronavirus (SARS-CoV) in China. ${ }^{1,2}$ And about a decade later, a new and emerging coronavirus was described in a patient from Saudi Arabia. ${ }^{3,4}$ The virus was identified as a novel coronavirus and later was named the Middle East respiratory syndrome coronavirus (MERS-CoV). ${ }^{5}$ These two coronaviruses shared multiple similarities in the epidemiology, clinical presentations, and posed challenges in prevention and management. 6,7 For any new emerging zoonotic pathogen, there are five stages in the evolution to cause diseases limited to humans. In stage 1 , the pathogen is confined to the animal host; in stage 2, human infections occur as a result of animal contacts; in stage 3 , there is a limited human-to-human transmission; stage 4 , there are multiple outbreaks with human-to-human transmission; and stage 5 , infections occur within humans. ${ }^{8}$ In this review, we describe the epidemiology, clinical features, and outcome of both SARS and MERS-CoV.

\section{The SARS-CoV and MERS-CoV}

SARS-CoV and MERS-CoV are enveloped positive strand RNA betacoronaviruses. The first coronavirus was isolated from humans in 1965 and was cultivated on human ciliated embryonal tracheal cells. ${ }^{9}$ Coronaviruses are enveloped, and positive stranded RNA viruses classified as a family within the Nidovirales order. There are four genera: $\alpha, \beta$, gamma, and delta, and human coronaviruses belong to the $\alpha$ or the $\beta$ genera. ${ }^{10}$ In 2002 , SARS-CoV outbreak was described and the virus was 50 to $60 \%$ identical and distantly related to known coronaviruses. ${ }^{11}$ The newly described virus was able
Issue Theme Community-Acquired Pneumonia: A Global Perspective; Guest Editors: Richard G. Wunderink, MD, and Charles Feldman, MBBCh, DSc, PhD, FRCP, FCP (SA)
Copyright (C) 2020 by Thieme Medical Publishers, Inc., 333 Seventh Avenue, New York, NY 10001, USA.

Tel: +1 (212) 760-0888.
DOI https://doi.org/ 10.1055/s-0040-1709160. ISSN 1069-3424. 
to cause disease in macaques with a similar spectrum of disease. ${ }^{12}$ While the MERS-CoV belongs to lineage $C$ betacoronavirus and emerged in September 2012 and continuous to cause sporadic cases and clusters of disease mostly in the Arabian Peninsula. ${ }^{13}$

\section{SARS Outbreak Evolution and Clinical Characteristics}

The initial description of the SARS outbreak was announced in November 2002 through non-official reports of the occurrence of an outbreak of respiratory illness in Guangdong Province, China, ${ }^{14}$ and few months later, this was reported to the World Health Organization (WHO). Analysis of the virus showed a point-source outbreak. ${ }^{15}$ The disease was recognized due to the occurrence of a cluster of atypical pneumonias occurring in Vietnam, Hong Kong, Canada, United States, and Singapore. ${ }^{1,16-23}$ All cases were linked to a patient who stayed in hotel $\mathrm{M}$ in Hong Kong, and subsequently, patients traveled from Hong Kong to Ireland, Vietnam, Singapore, United States, and Canada. ${ }^{24}$ This outbreak involved 30 countries in 6 continents and caused a total of 8,098 cases with a case fatality rate of $9.5 \% .{ }^{25}$ The clinical spectrum of the disease ranged from mild to severe disease requiring mechanical ventilation. ${ }^{26}$ The clinical picture followed an initial febrile illness, followed by a period of improvement then a clinical deterioration. ${ }^{27-29}$ The need for intensive care unit (ICU) care was described in 17 to $30 \%$ of SARS patients. ${ }^{28-30}$ In another study, $15 \%$ of SARS patients required mechanical ventilation. ${ }^{27}$ Patients also had extra-respiratory symptoms such as diarrhea. ${ }^{31}$ It was interesting to note that health care workers (HCWs) constituted $21 \%$ of all SARS cases. ${ }^{32-34}$ The disease was associated with $10 \%$ case fatality rate, ${ }^{35}$ and the presence of diabetes mellitus and other comorbidities was associated with increased fatality rates. ${ }^{30}$ SARS was thought to cause milder disease in children with no fatalities. ${ }^{36}$ One reason for the rapid spread of SARS was the occurrence of superspreaders. ${ }^{35}$ Superspreading event is described as the ability of certain individuals to infect a disproportionately large number of secondary patients relative to a typical infectious individual.

The origin of the SARS virus is thought to be animal and a similar virus was isolated from Himalayan palm civets (Paguma larvata), raccoon dogs (Nyctereutes procyonoides), and from a Chinese ferret badger (Melogale moschata) ${ }^{37}$ In addition, antibodies against SARS-CoV were found among wild animal traders in Guangdong Province. ${ }^{37,38}$ A seroprevalence of $72.7 \%$ was well known among those with trading history involving $P$. larvata. ${ }^{38}$ Although most patients with SARS had symptomatic disease, there are few seroprevalence studies and one study showed that $124(12 \%)$ of 1,030 individuals were positive by ELISA and $0.19 \%$ by the SARSspecific immunofluorescence assay (IFA). ${ }^{39}$ In another study, seroprevalence among HCWs was $2.3 \% 40$ and a meta-analysis showed an overall seroprevalence of $0.10 \% .{ }^{41}$ There were no approved therapeutic or preventative options for SARS, while a variety of therapeutic agents were used. ${ }^{42}$ SARS human cases disappeared abruptly by June 2003 with no approved vaccine or therapeutic agents developed or applied.

\section{MERS-CoV Evolution and Origin of the Virus}

The first case of MERS-CoV was reported in a businessman who lived in Bisha, Kingdom of Saudi Arabia (KSA) who presented to health care with pneumonia in early June 2012 and on transfer to a hospital in Jeddah, he rapidly succumbed to death within 10 days of diagnosis with multiorgan failure. The virus was later isolated and reported in September 2012 as the newly emerging MERS-CoV. As of January 2020, there have been a total of 2,468 cases of human MERS-CoV cases reported to WHO from 27 countries. More than $80 \%$ of cases have been reported from the Arabian Peninsula with KSA being the most affected country. There have been 851 reported mortalities with an overall case fatality rate of MERS-CoV estimated at 35\% (- Fig. 1). The exact origin of MERS-CoV is not known. However, MERS-CoV is likely to have originated from bats based on the isolation of other lineage $C \beta$-coronaviruses closely related to MERS-CoV and the isolation of a bat coronavirus that resembles MERS-CoV. Throat swabs, urine, feces, and serum samples were collected from wild bats in the KSA including the area where the first MERS-CoV patient had lived and worked. A 190-nucleotide fragment of the RNA-dependent RNA polymerase region of MERS-CoV genome was detected in one fecal pellet from an Egyptian tomb bat (Taphozous perforates). ${ }^{43}$ The amplified sequence was identical to that of the MERS-CoV sequence from the first index human case. ${ }^{43}$ The one-humped dromedaries (Camelus dromedarius) had been linked to MERS-CoV (-Fig. 2). Multiple studies showed high prevalence of MERSCoV antibodies in dromedary camels in the Arabian Peninsula, North Africa, and Eastern Africa. ${ }^{44-50}$ In addition, studies have shown that MERS-CoV antibodies were present in stored camel sera as early as early 1990s, suggesting the presence of MERS$\mathrm{CoV}$ in dromedaries for over 20 years before its first description in humans. ${ }^{50-52}$ MERS-CoV antibodies were detected more commonly among camels $>2$ years of age compared with younger camels. ${ }^{46,52-54}$ In addition, MERS-CoV was detected from respiratory tract samples by reverse transcriptase polymerase chain reaction (RT-PCR) in oronasal and fecal samples from dromedary camels in the Arabian Peninsula. ${ }^{52-58}$ In contrast to the MERS-CoV antibodies, juvenile camels shed more MERS-CoV as detected by PCR. ${ }^{52-55}$ In addition, viable MERS-CoV was isolated in cell cultures from nasal and fecal samples from dromedary camels. ${ }^{54,57,59-61}$ There had been studies documenting the isolation of similar and near-identical MERS-CoV strains from epidemiologically linked humans and dromedary camels. ${ }^{61-63}$ In addition, sequence of the MERS-CoV spike, ORF3-4a, and nucleocapsid regions were identical from asymptomatic contacts and their camels. ${ }^{64}$ The most recent common ancestor of all human MERS-CoV was found phylogenetically to date to the end of the year $2010 .{ }^{65}$ In addition, animal reservoir is geographically dispersed. ${ }^{66,67}$

\section{Clinical Features and Laboratory Findings}

The clinical and laboratory presentations of SARS-CoV and MERS-CoVare similar with some minor differences highlighted in - Table 1. The clinical picture of MERS-CoV cases ranges from asymptomatic to severe cases. In many cases, the presenting 


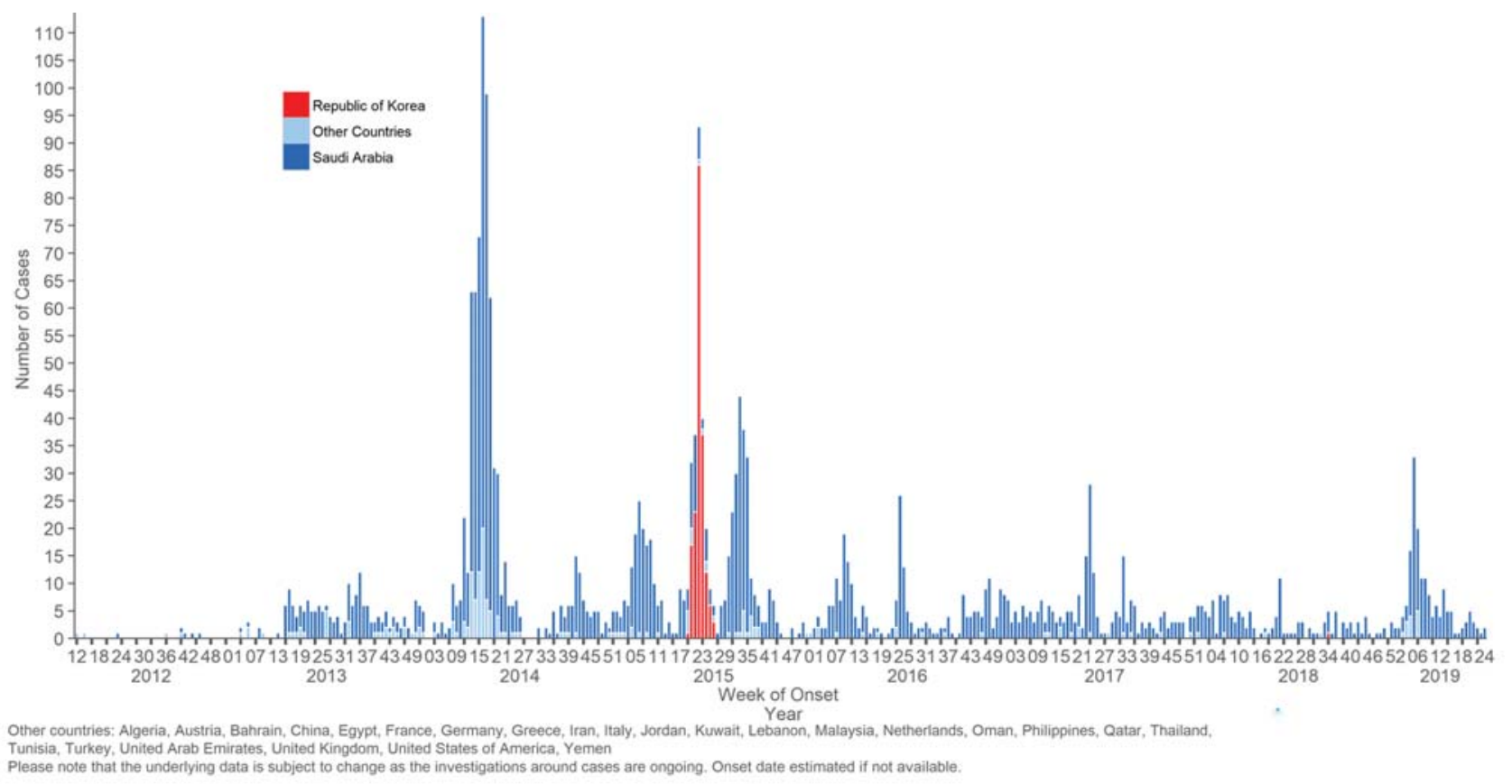

Fig. 1 Epicurve of confirmed global cases of MERS-CoV from September 2012 to July 16, 2019. MERS-CoV, Middle East respiratory syndrome coronavirus; WHO, World Health Organization.

symptoms are respiratory and 33\% of patients have gastrointestinal symptoms such as vomiting and diarrhea. ${ }^{68-73}$ Most hospitalized MERS-CoV patients present with fever, cough, and shortness of breath with clinical and radiological evidence of pneumonia. ${ }^{70-72,74}$ It seems that severe disease is a characteristic of primary cases, immunocompromised, and those with underlying comorbidities namely diabetes, kidney, and heart disease. In severe cases, there are multiple complications including respiratory and renal failure, acute liver injury, cardiac arrhythmias, and coagulopathy. ${ }^{69,70,73,75}$ There are few studies which showed no predictive signs or symptoms to differentiate patients with community-acquired pneumonia from those with MERS-CoV infection. ${ }^{72,76}$ The median incubation period was 5.2 days (95\% confidence interval [CI], 1.9-14.7), and the serial interval was 7.6 days (95\% CI,

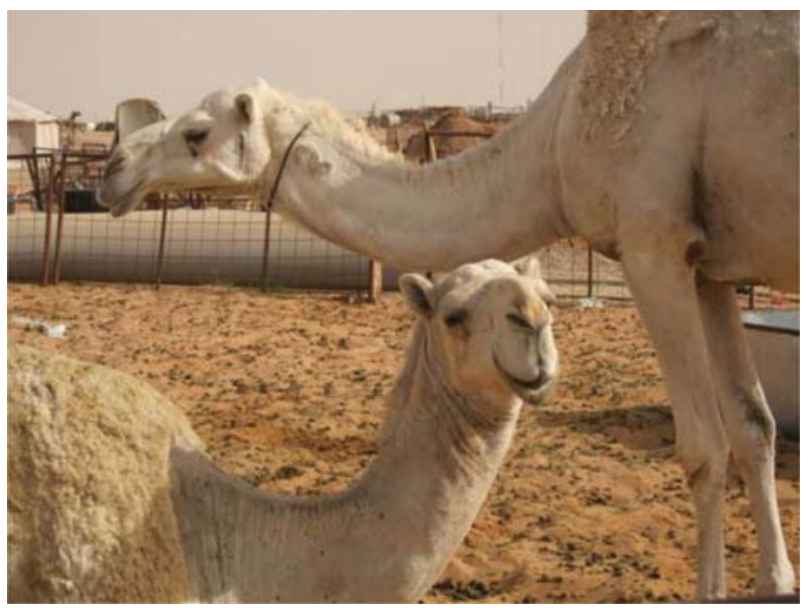

Fig. 2 Camels: a possible intermediary source of Middle Eastern respiratory syndrome coronavirus.
2.5-23.1) ${ }^{69}$ The median time to hospitalization, ICU admission, mechanical ventilation, and death were 5, 7, and 11 days, respectively. ${ }^{69,77}$ MERS-CoV carries a high case fatality rate (28.6-63.6\%) specially among elderly patients with several comorbidities, while in young healthy patients, they present with mild to no symptoms. ${ }^{71,78}$ One study found a lower case fatality rate similar to the rate reported in patients from South Korea of $9 \%{ }^{79,80}$ The variability of the case fatality rates may be related to host factors, associated comorbidities, care provided, and yet unidentified factors. ${ }^{78}$ In addition, the case fatality rate is inversely related to the percentage of asymptomatic cases as the percentage of these patients increased to $29 \%$, and the case fatality rate decreased to $30 \% .^{70,71,77,81-83}$ In addition, the case fatality rate is higher among critically ill patients ${ }^{76,78-80}$ comparing between MERS-CoV and non-MERS-CoV patients in relation to age, clinical, and laboratory features. ${ }^{72,76,84-86}$ In $\mathrm{KSA}$, extensive testing for MERS-CoV is being done over the past 6 years with $>50,000$ patients presenting to emergency care with respiratory symptoms being screened for MERS-CoV each year with a very low yield of $0.7 \%$ being positive. ${ }^{87}$ This excessive testing is applied in combination with a visual triage in all emergency rooms of all health care facilities (governmental and private) utilizing a clinical score cutoff of $>4$ for MERSCoV infection showing sensitivity and specificity of 74.1 and $18.6 \%$, respectively, in predicting MERS-CoV diagnosis. ${ }^{88}$

Predictors of 30-day mortality included factors such as age $>65$ years, being a non-HCW, the presence of preexisting comorbidities, presentation with severe disease, hospitalacquired infections, and corticosteroid use. ${ }^{70,89-91}$ The use of continuous renal replacement therapy and extracorporeal membrane oxygenation (ECMO) were additional risk factors for increased fatality. ${ }^{91-93}$ However, one study showed ECMO lowering in-hospital death. ${ }^{94}$ 
Table 1 Comparison of demographic, clinical, and laboratory features between MERS-CoV and SARS-CoV

\begin{tabular}{|c|c|c|}
\hline & MERS-CoV $8,36-39$ & SARS-CoV ${ }^{1,28,40}$ \\
\hline \multirow[t]{2}{*}{ Date of first case report (place) } & April 2012 (Jordan) & November 2002 (China) \\
\hline & June 2012 (first KSA case) & \\
\hline Incubation period & Mean: 5.2 d (95\% Cl: 1.9-14.7) & Mean: 4.6 d (95\% Cl: 3.8-5.8) \\
\hline Range: $2-13 \mathrm{~d}$ & Range: $2-14 \mathrm{~d}$ & \\
\hline Serial interval & $7.6 \mathrm{~d}$ & $8.4 \mathrm{~d}$ \\
\hline \multicolumn{3}{|l|}{ Age group } \\
\hline Adults & $98 \%$ & $93 \%$ \\
\hline Children & $2 \%$ & $5-7 \%$ \\
\hline Age $(y)$ : range, median & Range: 1-94; median: 50 & Range: 1-91; mean: 39.9 \\
\hline \multicolumn{3}{|l|}{ Mortality } \\
\hline CFR-overall & $41.8 \%$ & $9.6 \%$ \\
\hline CFR in patients with comorbidities & $13.3 \%$ & $1-2 \%$ \\
\hline Time from onset to death & Median $11.5 \mathrm{~d}$ & Mean 23.7d \\
\hline $\operatorname{Sex}(M, F)$ & M: 64.5\%, F: 35.5\% & M: 43\%, F: 57\% \\
\hline \multicolumn{3}{|l|}{ Presenting symptoms } \\
\hline Fever $>38^{\circ} \mathrm{C}$ & $98 \%$ & $99-100 \%$ \\
\hline Chills/rigors & $87 \%$ & $15-73 \%$ \\
\hline Cough & $83 \%$ & $62-100 \%$ \\
\hline Dry & $56 \%$ & $29-75 \%$ \\
\hline Productive & $44 \%$ & $4-29 \%$ \\
\hline Hemoptysis & $17 \%$ & $0-1 \%$ \\
\hline Headache & $11 \%$ & $20-56 \%$ \\
\hline Myalgia & $32 \%$ & $45-61 \%$ \\
\hline Malaise & $38 \%$ & $31-45 \%$ \\
\hline Shortness of breath & $72 \%$ & $40-42 \%$ \\
\hline Nausea & $21 \%$ & $20-35 \%$ \\
\hline Vomiting & $21 \%$ & $20-35 \%$ \\
\hline Diarrhea & $26 \%$ & $20-25 \%$ \\
\hline Sore throat & $14 \%$ & $13-25 \%$ \\
\hline Rhinorrhea & $6 \%$ & $2-24 \%$ \\
\hline Comorbidities & $76 \%$ & $10-30 \%$ \\
\hline Diabetes & $10 \%$ & $24 \%$ \\
\hline Chronic renal disease & $13 \%$ & $2-6 \%$ \\
\hline Chronic heart disease & $7.5 \%$ & $10 \%$ \\
\hline Malignancy & $2 \%$ & $3 \%$ \\
\hline Hypertension & $34 \%$ & $19 \%$ \\
\hline Obesity & $17 \%$ & $\mathrm{~N} / \mathrm{A}$ \\
\hline Smoking & $23 \%$ & $17 \%$ \\
\hline Viral hepatitis & Not known & $27 \%$ \\
\hline \multicolumn{3}{|l|}{ Laboratory results } \\
\hline CXR abnormalities & $100 \%$ & $94-100 \%$ \\
\hline Lymphopenia $\left(<1.5 \times 10^{9} / \mathrm{L}\right)$ & $32 \%$ & $68-85 \%$ \\
\hline Leukopenia $\left(<4.0 \times 10^{9} / \mathrm{L}\right)$ & $14 \%$ & $25-35 \%$ \\
\hline
\end{tabular}


Table 1 (Continued)

\begin{tabular}{|l|l|l|}
\hline & MERS-CoV $8,36-39$ & SARS-CoV \\
\hline Thrombocytopenia $\left(<140 \times 10^{9} / \mathrm{L}\right)$ & $36 \%$ & $40-45 \%$ \\
\hline Elevated LDH & $48 \%$ & $50-71 \%$ \\
\hline Elevated ALT & $11 \%$ & $20-30 \%$ \\
\hline Elevated AST & $14 \%$ & $20-30 \%$ \\
\hline Ventilatory support required & $80 \%$ & $14-20 \%$ \\
\hline
\end{tabular}

Abbreviations: ALT, alanine aminotransferase; AST, aspartate aminotransferase; CFR, case fatality rate; CI, confidence interval; CXR, chest X-ray; KSA, Kingdom of Saudi Arabia; LDH, lactate dehydrogenase; MERS-CoV; Middle East respiratory syndrome coronavirus; SARS-CoV, severe acute respiratory syndrome coronavirus.

Source: Reproduced with permission from Hui et al. ${ }^{161}$

\section{Laboratory Tests}

The diagnosis of MERS-CoV infection relies on the confirmation by real-time reverse transcriptase PCR of respiratory tract samples. Lower respiratory samples provide better yield and is the sample source of choice for testing. ${ }^{95,96}$ However, a single negative test should not rule out infection and a repeat testing is indicated as some patients may have intermittent positive tests. ${ }^{97}$ Serologic testing for MERS-CoV utilizes IFA, serum neutralization, or protein microarray assays to detect MERS-CoV antibodies. ${ }^{98}$ The utility of serodiagnosis relies on two serum samples taken 14 days or more apart. Serodiagnosis begins with a screening ELISA or IFA and a confirmatory neutralization assay. ${ }^{99-101}$ Testing for MERSCoV by PCR detected the virus in the patient serum, urine, and feces but at a much lower level than those found in the lower respiratory tract. ${ }^{102}$ Patients with MERS-CoV infection had abnormal laboratory findings including: leukopenia, lymphopenia, thrombocytopenia, and elevated hepatic enzymes. ${ }^{68,71,72,76,103}$ A risk analysis showed that the following were associated with increased risk of death: presence of comorbidity (relative risk $[R R]=3$ ), male gender $(R R=1.6)$, exposure to dromedary camels $(R R=1.6)$, and consumption of camel milk $(R R=1.5){ }^{104}$ Overall, over the past 7 years, $50 \%$ of MERS-CoV cases reported to WHO were associated with human-to-human transmission in hospitals. Among 61 MERS-CoV patients presenting with MERS-CoV in 2017, 9 (15\%) were associated with a hospital outbreak, 10 (16\%) were household contacts, and 42 (69\%) were sporadic cases. Of the 42 sporadic cases, $50 \%$ had camel contact. ${ }^{105}$ In an outbreak investigation of a cluster of MERS cases in a nonhealth care-associated setting, 18 (2.2\%) of 828 contacts were positive for MERS-CoV infections. ${ }^{106}$ This rate was similar to household contact study of $4.3 \%{ }^{101}$

\section{Intrahospital Transmission}

Health care-associated infection is the hallmark of the transmission of MERS-CoV between patients and from patients to HCWs. ${ }^{69,70,74,81,107-123}$ Of the factors contributing to intrahospital transmission is the occurrence of superspreading events. In the outbreak in the Republic of Korea, three patients were epidemiologically connected to $73 \%$ of the transmissions and each infected 23, 28, and 85 individuals. ${ }^{124}$ In addition, superspreader phenomena also occurred in the first reported outbreak in Al-Hasa, Saudi Arabia. ${ }^{69}$ A recent systematic review outlined the contributing factors to health care-associated MERS-CoV transmissions and included: absent physical barriers between beds, inadequate isolation of suspected MERS patients, lack of isolation and negative pressure rooms, unfamiliarity and underrecognition of MERS infection, insufficient compliance with infection control measures, aerosol generating procedures, presence of multiple friends and family members in the patient's room, and the phenomena of "medical shopping." 125 HCWs may act as contributors to the spread of MERS-CoV infection. In one study, MERS-CoV PCR was positive in $4.5 \%$ among exposed HCWs ${ }^{126}$ and another study showed 15 (1.3\%) of 1,169 HCWs were positive by PCR and 5 $(0.68 \%)$ of 737 HCWs were positive by serology. ${ }^{127}$ Other studies showed none of 38 HCWs was positive by serology 128 and none of 48 contacts was positive. ${ }^{129}$ In Korea, 36 (19.9\%) of 181 confirmed MERS-CoV cases were HCWs. ${ }^{130}$ However, studies had showed that most positive HCWs were asymptomatic or had mild disease. ${ }^{131}$ Although major hospital outbreaks were thought to be linked to intrahospital transmission of MERS-CoV, MERS-CoV genome sequence in these outbreaks showed multiple introductions of the virus with human-tohuman transmissions. ${ }^{66,67,69}$ There were three distinct MERSCoV genotypes. ${ }^{67}$

\section{Seasonality of MERS-CoV}

The emergence of MERS-CoV had led to many speculations regarding the seasonality of this disease and initially thought to occur mostly in March-May and SeptemberNovember. ${ }^{81,132,133}$ One reason for such a significant increase in April-May 2014 was a large outbreak in Jeddah, Saudi Arabia. ${ }^{107}$ However, seasonal variation may be the result of seasonality in the calving of dromedaries in November and March. ${ }^{10,44,46,48,52,55,77,82,83,134}$ Such a concept was studied and it was found that the prevalence of MERS-CoV was higher in camels in the winter (71.5\%) than the summer season (6.2\%). ${ }^{135}$ Looking at all MERS-CoV cases from 2012 to 2016, the mean monthly cases were 
higher in the winter and summer months. ${ }^{136}$ Evaluation of cases from January 2013 and December 2017 included a total of 2,025 cases and showed a noteworthy decrease in the annual cases in 2016 to $2017 .{ }^{137}$ Of all the 2,025 cases, $38.2 \%$ occurred in the Spring and $36.4 \%$ occurred in the Summer. ${ }^{137}$ However, there was no variation on the number of cases per year, and either per month or per season. ${ }^{137}$

\section{Therapeutic Options}

Currently, there is no approved therapy for MERS-CoV infection. Studies showed superiority of interferon (IFN)- $\beta$ compared with other IFN types ${ }^{138}$ and that polyethylene glycol IFN- $\alpha$ had excellent cytopathic inhibitory effect. ${ }^{139}$ In addition, the combination of INF- $\alpha 2 b$ and ribavirin showed augmentation of action and lower concentrations of IFN$\alpha 2 \mathrm{~b}$ and ribavirin were required. ${ }^{140}$ However, the data from clinical use of these two agents in retrospective studies showed no therapeutic advantages of these on survival of patients. ${ }^{42,141-145} \mathrm{~A}$ retrospective analysis showed that using INF to treat patients with positive MERS-CoV RT-PCR was associated with a case fatality rate of $90 \%$ compared with $44 \%$ in those with negative MERS-CoV RT-PCR test. ${ }^{68}$ Another study showed survival rates of $78.3,75$, and $68.4 \%$ using IFN$\beta$, IFN- $\alpha$, and ribavirin, respectively. ${ }^{146}$ The use of the antiretroviral therapy for MERS-CoV was tried using pegylated IFN, ribavirin, and lopinavir/ritonavir ${ }^{143}$ and another eight patients received mycophenolate mofetil and the latter patients survived. ${ }^{146} \mathrm{~A}$ randomized controlled trial using a combination of lopinavir-ritonavir and IFN- $\beta 1 \mathrm{~b}$ is being conducted. $^{147}$

\section{Seroprevalence of MERS-CoV}

Although MERS-CoV PCR testing is the main methodology for the diagnosis of MERS-CoV infection, serologic tests confirmed $8(6.4 \%)$ of 124 Jordanian contacts who were positive. ${ }^{119}$ Seroprevalence of 356 abattoir workers and blood donors found that $8(2.2 \%)$ were weakly positive by immunofluorescence assay (IFA), and none was had positive neutralization titers. ${ }^{148} \mathrm{~A}$ seroprevalence study found none of 268 children with respiratory tract infections to be positive. ${ }^{149}$ In an evaluation of 280 household contacts, 12 (4.3\%) were probable cases by serology. ${ }^{101}$ However, in a population-based survey of 10,000 samples, the seroprevalence was $0.15 \%$ and the camel shepherd and abattoir workers had 17 and 26-fold increase in seroprevalence in comparison to the general population. ${ }^{150}$

\section{Infection Control}

MERS-CoV is stable in the environment and can survive on plastic and steel for up to 48 hours at lower temperature and humidity. However, MERS-CoV is less viable at higher temperature and humidity. ${ }^{151}$ This finding was confirmed by another study where a temperature of $65^{\circ} \mathrm{C}$ had a strong negative effect on viral infectivity compared with a temperature of $25^{\circ} \mathrm{C}{ }^{152}$ In the hospital setting, WHO advocates contact and droplet precautions with airborne isolation when dealing with aerosol-generating procedures. ${ }^{153,154}$ However, both the United States and the European Centre for Disease Prevention and Control recommend the use of airborne infection isolation precautions. ${ }^{155}$

\section{MERS and Camel Connections}

In a recent study from Egypt, Senegal, Tunisia, Uganda, Jordan, Saudi Arabia, and Iraq, MERS-CoV was detected in camels using either PCR or serology. ${ }^{156}$ The positivity rate using PCR ranged from 0\% in Uganda, Jordan, and Iraq to $3.1 \%$ in Saudi Arabia, 5.5\% in Senegal, and 8.2\% in Egypt. ${ }^{156}$ It was shown that seropositivity is very high (84.5\%) among tested camels compared with PCR positivity of $3.8 \% .157$ Studies from Saudi Arabia showed either no significant difference in seropositivity of MERS-CoV in camels in different regions ${ }^{156}$ or had detected variable seropositivity to MERS-CoV (37-100\%). ${ }^{158}$ It is worth mentioning that Somalia and Sudan are the main source of imported camels into Saudi Arabia. ${ }^{156}$

The seroprevalence of MERS-CoV is lower (30.3\%) in juvenile camels $(<2$ years of age) compared with adult camels $(82.6 \%)^{156}$ as described in the previous studies. ${ }^{53}$ Also, the detection rate of MERS-CoV RNA by PCR is higher in adults $(16.1 \%)$ compared with juvenile camels (1.7\%). ${ }^{156}$ What is unusual is the ability of MERS-CoV to causes reinfection of camels in the presence of antibodies. ${ }^{56,156}$ Another important finding of MERS-CoV in camels is that camels rarely show signs of infection. ${ }^{156,159}$ Although it has been postulated that drinking camel milk is one of the key sources of infection in the Arabian peninsula, a study found no MERS-CoV in the urine of naturally infected camels. ${ }^{160}$

\section{Conclusion}

Emerging respiratory viruses, specially MERS-CoV, continue to challenge the public health infrastructure of countries of the Arabian Peninsula with the risk of transmission and outbreaks in other countries though travel. Although it is still debated by some, bats appear to be the common natural source of both SARS and MERS. There are considerable similarities in the clinical features of both MERS-CoV and SARS-CoV, but MERS tends to progress much faster to respiratory failure than SARS. Although SARS-CoV clinical cases disappeared since mid-2003, both MERS-CoV and SARS-CoV are still listed as priority pathogens by the WHO research and development blueprint. The case fatality rate of MERS-CoV is much higher and likely related to older age and comorbid illness of the sporadic cases. Several gaps continue in our knowledge about disease prevention and treatment, and more studies are needed to understand the pathogenesis, viral kinetics, mode of disease transmission, any other intermediary source, and treatment options of MERS to guide public health infection control measures and treatment.

Conflict of Interest

None declared. 


\section{References}

1 Lee $\mathrm{N}$, Hui $\mathrm{D}, \mathrm{Wu} \mathrm{A}$, et al. A major outbreak of severe acute respiratory syndrome in Hong Kong. N Engl J Med 2003;348(20): 1986-1994

2 Shaw K. The 2003 SARS outbreak and its impact on infection control practices. Public Health 2006;120(01):8-14

3 Zaki AM, van Boheemen S, Bestebroer TM, Osterhaus AD, Fouchier RA. Isolation of a novel coronavirus from a man with pneumonia in Saudi Arabia. N Engl J Med 2012;367(19):1814-1820

4 Corman VM, Eckerle I, Bleicker T, et al. Detection of a novel human coronavirus by real-time reverse-transcription polymerase chain reaction. Euro Surveill 2012;17(39):17

5 de Groot RJ, Baker SC, Baric RS, et al. Middle East respiratory syndrome coronavirus (MERS-CoV): announcement of the Coronavirus Study Group. J Virol 2013;87(14):7790-7792

6 Al-Tawfiq JA, Zumla A, Memish ZA. Coronaviruses: severe acute respiratory syndrome coronavirus and Middle East respiratory syndrome coronavirus in travelers. Curr Opin Infect Dis 2014;27 (05):411-417

7 Al-Tawfiq JA, Zumla A, Gautret P, et al. Surveillance for emerging respiratory viruses. Lancet Infect Dis 2014;14(10):992-1000

8 Wolfe ND, Dunavan CP, Diamond J. Origins of major human infectious diseases. Nature 2007;447(7142):279-283

9 Tyrrell DA, Bynoe ML. Cultivation of a novel type of common-cold virus in organ cultures. BMJ 1965;1(5448):1467-1470

10 Chan JF, Lau SK, To KK, Cheng VC, Woo PC, Yuen K-Y. Middle East respiratory syndrome coronavirus: another zoonotic betacoronavirus causing SARS-like disease. Clin Microbiol Rev 2015;28 (02):465-522

11 Drosten C, Günther S, Preiser W, et al. Identification of a novel coronavirus in patients with severe acute respiratory syndrome. N Engl J Med 2003;348(20):1967-1976

12 Kuiken T, Fouchier RA, Schutten M, et al. Newly discovered coronavirus as the primary cause of severe acute respiratory syndrome. Lancet 2003;362(9380):263-270

13 van Boheemen S, de Graaf M, Lauber C, et al. Genomic characterization of a newly discovered coronavirus associated with acute respiratory distress syndrome in humans. MBio 2012;3 (06):e00473-e12

14 Cheng VC, Lau SK, Woo PC, Yuen KY. Severe acute respiratory syndrome coronavirus as an agent of emerging and reemerging infection. Clin Microbiol Rev 2007;20(04):660-694

15 Ksiazek TG, Erdman D, Goldsmith CS, et al; SARS Working Group. A novel coronavirus associated with severe acute respiratory syndrome. N Engl J Med 2003;348(20):1953-1966

16 Leung GM, Hedley AJ, Ho L-M, et al. The epidemiology of severe acute respiratory syndrome in the 2003 Hong Kong epidemic: an analysis of all 1755 patients. Ann Intern Med 2004;141(09):662-673

17 Tsang KW, Ho PL, Ooi GC, et al. A cluster of cases of severe acute respiratory syndrome in Hong Kong. N Engl J Med 2003;348(20): 1977-1985

18 Poutanen SM, Low DE, Henry B, et al; National Microbiology Laboratory, Canada; Canadian Severe Acute Respiratory Syndrome Study Team. Identification of severe acute respiratory syndrome in Canada. N Engl J Med 2003;348(20):1995-2005

19 Centers for Disease Control and Prevention (CDC). Outbreak of severe acute respiratory syndrome-worldwide, 2003. MMWR Morb Mortal Wkly Rep 2003;52(11):226-228

20 Centers for Disease Control and Prevention (CDC). Preliminary clinical description of severe acute respiratory syndrome. MMWR Morb Mortal Wkly Rep 2003;52(12):255-256

21 Centers for Disease Control and Prevention (CDC). Update: severe acute respiratory syndrome-United States, June 4, 2003. MMWR Morb Mortal Wkly Rep 2003;52(22):525-526

22 Centers for Disease Control and Prevention (CDC). Severe acute respiratory syndrome (SARS) and coronavirus testing-United States, 2003. MMWR Morb Mortal Wkly Rep 2003;52(14):297-302
23 Centers for Disease Control and Prevention (CDC). Severe acute respiratory syndrome-Singapore, 2003. MMWR Morb Mortal Wkly Rep 2003;52(18):405-411

24 Parashar UD, Anderson LJ. Severe acute respiratory syndrome: review and lessons of the 2003 outbreak. Int J Epidemiol 2004;33 (04):628-634

25 World Health Organization (WHO). Summary of probable SARS cases with onset of illness from 1 November 2002 to 31 July 2003. WHO; 2015

26 Chiang C-H, Shih J-F, Su W-J, Perng R-P. Eight-month prospective study of 14 patients with hospital-acquired severe acute respiratory syndrome. Mayo Clin Proc 2004;79(11):1372-1379

27 Sung JJ, Wu A, Joynt GM, et al. Severe acute respiratory syndrome: report of treatment and outcome after a major outbreak. Thorax 2004;59(05):414-420

28 Hsu L-Y, Lee C-C, Green JA, et al. Severe acute respiratory syndrome (SARS) in Singapore: clinical features of index patient and initial contacts. Emerg Infect Dis 2003;9(06):713-717

29 Peiris JS, Chu CM, Cheng VC, et al; HKU/UCH SARS Study Group. Clinical progression and viral load in a community outbreak of coronavirus-associated SARS pneumonia: a prospective study. Lancet 2003;361(9371):1767-1772

30 Booth CM, Matukas LM, Tomlinson GA, et al. Clinical features and short-term outcomes of 144 patients with SARS in the greater Toronto area. [see comment] [erratum appears in JAMA $2003 \mathrm{Jul}$ 16;290(3):334]JAMA 2003;289(21):2801-2809

31 Kwan YW, Leung CW, Chiu MC. Diarrhoea as the presenting sign in an adolescent suffering from severe acute respiratory syndrome. Eur J Pediatr 2005;164(04):227-230

32 Nuttall I, Dye C. Epidemiology. The SARS wake-up call. Science 2013;339(6125):1287-1288

33 Nuttall I, Dye C. Epidemiology. The SARS wake-up call. Science 2013;339(6125):1287-1288

34 Cameron PA, Rainer TH. SARS: a wake up call for a health care system under stress. Emerg Med (Fremantle) 2003;15(56):409-412

35 Lapinsky SE, Granton JT. Critical care lessons from severe acute respiratory syndrome. Curr Opin Crit Care 2004;10(01):53-58

36 Leung CW, Chiu WK. Clinical picture, diagnosis, treatment and outcome of severe acute respiratory syndrome (SARS) in children. Paediatr Respir Rev 2004;5(04):275-288

37 Guan Y, Zheng BJ, He YQ, et al. Isolation and characterization of viruses related to the SARS coronavirus from animals in southern China. Science 2003;302(5643):276-278

38 Centers for Disease Control and Prevention (CDC). Prevalence of IgG antibody to SARS-associated coronavirus in animal tradersGuangdong Province, China, 2003. MMWR Morb Mortal Wkly Rep 2003;52(41):986-987

39 Tsai M-H, Lin T-Y, Chiu C-H, et al. Seroprevalence of SARS coronavirus among residents near a hospital with a nosocomial outbreak. J Formos Med Assoc 2008;107(11):885-891

40 Ip M, Chan PK, Lee N, et al. Seroprevalence of antibody to severe acute respiratory syndrome (SARS)-associated coronavirus among health care workers in SARS and non-SARS medical wards. Clin Infect Dis 2004;38(12):e116-e118

41 Leung GM, Lim WW, Ho LM, et al. Seroprevalence of IgG antibodies to SARS-coronavirus in asymptomatic or subclinical population groups. Epidemiol Infect 2006;134(02): 211-221

42 Momattin H, Mohammed K, Zumla A, Memish ZA, Al-Tawfiq JA. Therapeutic options for Middle East respiratory syndrome coronavirus (MERS-CoV)-possible lessons from a systematic review of SARS-CoV therapy. Int J Infect Dis 2013;17(10): e792-e798

43 Memish ZA, Mishra N, Olival KJ, et al. Middle East respiratory syndrome coronavirus in bats, Saudi Arabia. Emerg Infect Dis 2013;19(11):1819-1823 
44 Reusken CB, Haagmans BL, Müller MA, et al. Middle East respiratory syndrome coronavirus neutralising serum antibodies in dromedary camels: a comparative serological study. Lancet Infect Dis 2013;13(10):859-866

45 Reusken $\mathrm{CB}$, Ababneh M, Raj VS, et al. Middle East respiratory syndrome coronavirus (MERS-CoV) serology in major livestock species in an affected region in Jordan, June to September 2013. Euro Surveill 2013;18(50):20662

46 Hemida MG, Perera RA, Wang P, et al. Middle East respiratory syndrome (MERS) coronavirus seroprevalence in domestic livestock in Saudi Arabia, 2010 to 2013. Euro Surveill 2013;18(50): 20659

47 Alexandersen S, Kobinger GP, Soule G, Wernery U. Middle East respiratory syndrome coronavirus antibody reactors among camels in Dubai, United Arab Emirates, in 2005. Transbound Emerg Dis 2014;61(02):105-108

48 Reusken CB, Messadi L, Feyisa A, et al. Geographic distribution of MERS coronavirus among dromedary camels, Africa. Emerg Infect Dis 2014;20(08):1370-1374

49 Nowotny N, Kolodziejek J. Middle East respiratory syndrome coronavirus (MERS-CoV) in dromedary camels, Oman, 2013. Euro Surveill 2014;19(16):20781

50 Corman VM, Jores J, Meyer B, et al. Antibodies against MERS coronavirus in dromedary camels, Kenya, 1992-2013. Emerg Infect Dis 2014;20(08):1319-1322

51 Hemida MG, Perera RA, Al Jassim RA, et al. Seroepidemiology of Middle East respiratory syndrome (MERS) coronavirus in Saudi Arabia (1993) and Australia (2014) and characterisation of assay specificity. Euro Surveill 2014;19(23):19

52 Alagaili AN, Briese T, Mishra N, et al. Middle East respiratory syndrome coronavirus infection in dromedary camels in Saudi Arabia. MBio 2014;5(02):e00884-e14

53 Hemida MG, Alnaeem A, Chu DK, et al. Longitudinal study of Middle East respiratory syndrome coronavirus infection in dromedary camel herds in Saudi Arabia, 2014-2015. Emerg Microbes Infect 2017;6(06):e56

54 Wernery U, Corman VM, Wong EY, et al. Acute Middle East respiratory syndrome coronavirus infection in livestock Dromedaries, Dubai, 2014. Emerg Infect Dis 2015;21(06):1019-1022

55 Khalafalla AI, Lu X, Al-Mubarak AI, Dalab AH, Al-Busadah KA, Erdman DD. MERS-CoV in upper respiratory tract and lungs of dromedary camels, Saudi Arabia, 2013-2014. Emerg Infect Dis 2015;21(07):1153-1158

56 Farag EA, Reusken CB, Haagmans BL, et al. High proportion of MERS-CoV shedding dromedaries at slaughterhouse with a potential epidemiological link to human cases, Qatar 2014. Infect Ecol Epidemiol 2015;5:28305

57 Raj VS, Farag EA, Reusken CB, et al. Isolation of MERS coronavirus from a dromedary camel, Qatar, 2014. Emerg Infect Dis 2014;20 (08):1339-1342

58 Yusof MF, Eltahir YM, Serhan WS, et al. Prevalence of Middle East respiratory syndrome coronavirus (MERS-CoV) in dromedary camels in Abu Dhabi Emirate, United Arab Emirates. Virus Genes 2015;50(03):509-513

59 Hemida MG, Chu DK, Poon LL, et al. MERS coronavirus in dromedary camel herd, Saudi Arabia. Emerg Infect Dis 2014; 20(07):1231-1234

60 Briese T, Mishra N, Jain K, et al. Middle East respiratory syndrome coronavirus quasispecies that include homologues of human isolates revealed through whole-genome analysis and virus cultured from dromedary camels in Saudi Arabia. MBio 2014;5(03):e01146-e14

61 Haagmans BL, Al Dhahiry SH, Reusken CB, et al. Middle East respiratory syndrome coronavirus in dromedary camels: an outbreak investigation. Lancet Infect Dis 2014;14(02):140-145

62 Memish ZA, Cotten M, Meyer B, et al. Human infection with MERS coronavirus after exposure to infected camels, Saudi Arabia, 2013. Emerg Infect Dis 2014;20(06):1012-1015
63 Azhar EI, El-Kafrawy SA, Farraj SA, et al. Evidence for camel-tohuman transmission of MERS coronavirus. N Engl J Med 2014; 370(26):2499-2505

64 Al Hammadi ZM, Chu DK, Eltahir YM, et al. Asymptomatic MERS$\mathrm{CoV}$ infection in humans possibly linked to infected dromedaries imported from Oman to United Arab Emirates, May 2015. Emerg Infect Dis 2015;21(12):2197-2200

65 Lau SKP, Wong ACP, Lau TCK, Woo PCY. Molecular evolution of MERS coronavirus: dromedaries as a recent intermediate host or long-time animal reservoir? Int J Mol Sci 2017;18(10):E2138

66 Cotten M, Watson SJ, Zumla AI, et al. Spread, circulation, and evolution of the Middle East respiratory syndrome coronavirus. MBio 2014;5(01):e01062-e13

67 Cotten M, Watson SJ, Kellam P, et al. Transmission and evolution of the Middle East respiratory syndrome coronavirus in Saudi Arabia: a descriptive genomic study. Lancet 2013;382(9909):1993-2002

68 Shalhoub S, Farahat F, Al-Jiffri A, et al. IFN- $\alpha 2 a$ or IFN- $\beta 1$ a in combination with ribavirin to treat Middle East respiratory syndrome coronavirus pneumonia: a retrospective study. J Antimicrob Chemother 2015;70(07):2129-2132

69 Assiri A, McGeer A, Perl TM, et al; KSA MERS-CoV Investigation Team. Hospital outbreak of Middle East respiratory syndrome coronavirus. N Engl J Med 2013;369(05):407-416

70 Saad M, Omrani AS, Baig K, et al. Clinical aspects and outcomes of 70 patients with Middle East respiratory syndrome coronavirus infection: a single-center experience in Saudi Arabia. Int J Infect Dis 2014;29:301-306

71 Assiri A, Al-Tawfiq JA, Al-Rabeeah AA, et al. Epidemiological, demographic, and clinical characteristics of 47 cases of Middle East respiratory syndrome coronavirus disease from Saudi Arabia: a descriptive study. Lancet Infect Dis 2013;13(09):752-761

72 Al-Tawfiq JA, Hinedi K, Ghandour J, et al. Middle East respiratory syndrome coronavirus: a case-control study of hospitalized patients. Clin Infect Dis 2014;59(02):160-165

73 Arabi YM, Arifi AA, Balkhy HH, et al. Clinical course and outcomes of critically ill patients with Middle East respiratory syndrome coronavirus infection. Ann Intern Med 2014;160(06):389-397

74 Fagbo SF, Skakni L, Chu DK, et al. Molecular epidemiology of hospital outbreak of Middle East respiratory syndrome, Riyadh, Saudi Arabia, 2014. Emerg Infect Dis 2015;21(11):1981-1988

75 Al-Hameed F, Wahla AS, Siddiqui S, et al. Characteristics and outcomes of Middle East respiratory syndrome coronavirus patients admitted to an intensive care unit in Jeddah, Saudi Arabia. J Intensive Care Med 2016;31(05):344-348

76 Al-Tawfiq JA, Alfaraj SH, Altuwaijri TA, Memish ZA. A cohortstudy of patients suspected for MERS-CoV in a referral hospital in Saudi Arabia. J Infect 2017;75(04):378-379

77 The WHO Mers-Cov Research Group. State of Knowledge and Data Gaps of Middle East Respiratory Syndrome Coronavirus (MERS-CoV) in Humans. PLoS Curr 2013;5:pii: ecurrents. outbreaks.0bf719e352e7478f8ad85fa30

78 Nam H-S, Park JW, Ki M, Yeon M-Y, Kim J, Kim SW. High fatality rates and associated factors in two hospital outbreaks of MERS in Daejeon, the Republic of Korea. Int J Infect Dis 2017;58:37-42

79 Kim KH, Tandi TE, Choi JW, Moon JM, Kim MS. Middle East respiratory syndrome coronavirus (MERS-CoV) outbreak in South Korea, 2015: epidemiology, characteristics and public health implications. J Hosp Infect 2017;95(02):207-213

80 Choi WS, Kang C-I, Kim Y, et al; Korean Society of Infectious Diseases. Clinical presentation and outcomes of Middle East respiratory syndrome in the Republic of Korea. Infect Chemother 2016;48(02):118-126

81 Al-Tawfiq JA, Memish ZA. Drivers of MERS-CoV transmission: what do we know? Expert Rev Respir Med 2016;10(03):331-338

82 Al-Tawfiq JA, Memish ZA. Middle East respiratory syndrome coronavirus: epidemiology and disease control measures. Infect Drug Resist 2014;7:281-287 
83 Penttinen PM, Kaasik-Aaslav K, Friaux A, et al. Taking stock of the first 133 MERS coronavirus cases globally-is the epidemic changing? Euro Surveill 2013;18(39):18

84 Mohd HA, Memish ZA, Alfaraj SH, et al. Predictors of MERS-CoV infection: a large case control study of patients presenting with ILI at a MERS-CoV referral hospital in Saudi Arabia. Travel Med Infect Dis 2016;14(05):464-470

85 Garbati MA, Fagbo SF, Fang VJ, et al. A comparative study of clinical presentation and risk factors for adverse outcome in patients hospitalised with acute respiratory disease due to MERS coronavirus or other causes. PLoS One 2016;11(11):e0165978

86 Command and Control Center Ministry of Health Kingdom of Saudi Arabia Scientific Advisory Board. Infection Prevention and Control Guidelines for the Middle East Respiratory Syndrome Coronavirus (MERS-CoV) Infection, 4th Edition. 2017. Available at: http://www.moh.gov.sa/endepts/Infection/Documents/ Guidelines-for-MERS-CoV.PDF. Accessed May 12, 2017

87 Saeed AA, Abedi GR, Alzahrani AG, et al. Surveillance and testing for Middle East respiratory syndrome coronavirus, Saudi Arabia, April 2015-February 2016. Emerg Infect Dis 2017;23(04): 682-685

88 Alfaraj SH, Al-Tawfiq JA, Gautret P, Alenazi MG, Asiri AY, Memish ZA. Evaluation of visual triage for screening of Middle East respiratory syndrome coronavirus patients. New Microbes New Infect 2018;26:49-52

89 Ahmed AE. The predictors of 3- and 30-day mortality in 660 MERS-CoV patients. BMC Infect Dis 2017;17(01):615

90 Arabi YM, Mandourah Y, Al-Hameed F, et al; Saudi Critical Care Trial Group. Corticosteroid therapy for critically ill patients with Middle East respiratory syndrome. Am J Respir Crit Care Med 2018;197(06):757-767

91 Alfaraj SH, Al-Tawfiq JA, Assiri AY, Alzahrani NA, Alanazi AA, Memish ZA. Clinical predictors of mortality of Middle East respiratory syndrome coronavirus (MERS-CoV) infection: a cohort study. Travel Med Infect Dis 2019;29:48-50

92 Cha R-H, Joh J-S, Jeong I, et al; Critical Care Team of National Medical Center. Renal complications and their prognosis in Korean patients with Middle East respiratory syndrome-coronavirus from the Central MERS-CoV Designated Hospital. J Korean Med Sci 2015;30(12):1807-1814

93 Arabi YM, Al-Omari A, Mandourah Y, et al; Saudi Critical Care Trial Group. Critically ill patients with the Middle East respiratory syndrome: a multicenter retrospective cohort study. Crit Care Med 2017;45(10):1683-1695

94 Alshahrani MS, Sindi A, Alshamsi F, et al. Extracorporeal membrane oxygenation for severe Middle East respiratory syndrome coronavirus. Ann Intensive Care 2018;8(01):3

95 Memish ZA, Al-Tawfiq JA, Makhdoom HQ et al. Respiratory tract samples, viral load, and genome fraction yield in patients with Middle East respiratory syndrome. J Infect Dis 2014;210(10): 1590-1594

96 Al-Tawfiq JA, Hinedi $\mathrm{K}$. The calm before the storm: clinical observations of Middle East respiratory syndrome (MERS) patients. J Chemother 2018;30(03):179-182

97 Alfaraj SH, Al-Tawfiq JA, Memish ZA. Middle East respiratory syndrome coronavirus intermittent positive cases: implications for infection control. Am J Infect Control 2019;47(03): 290-293

98 Corman VM, Müller MA, Costabel U, et al. Assays for laboratory confirmation of novel human coronavirus (hCoV-EMC) infections. Euro Surveill 2012;17(49):49

99 World Health Organization (WHO). Middle East respiratory syndrome coronavirus: case definition for reporting to WHO. WHO; 2017

100 Buchholz U, Müller MA, Nitsche A, et al. Contact investigation of a case of human novel coronavirus infection treated in a German hospital, October-November 2012. Euro Surveill 2013;18(08):18
101 Drosten C, Meyer B, Müller MA, et al. Transmission of MERScoronavirus in household contacts. N Engl J Med 2014;371(09): 828-835

102 Drosten C, Seilmaier M, Corman VM, et al. Clinical features and virological analysis of a case of Middle East respiratory syndrome coronavirus infection. Lancet Infect Dis 2013;13(09): 745-751

103 Omrani AS, Matin MA, Haddad Q, Al-Nakhli D, Memish ZA, Albarrak AM. A family cluster of Middle East respiratory syndrome coronavirus infections related to a likely unrecognized asymptomatic or mild case. Int J Infect Dis 2013;17(09): e668-e672

104 Rahman A, Sarkar A. Risk factors for fatal Middle East respiratory syndrome coronavirus infections in Saudi Arabia: analysis of the WHO line list, 2013-2018. Am J Public Health 2019;109(09): 1288-1293

105 Hakawi A, Rose EB, Biggs HM, et al. Middle East respiratory syndrome coronavirus, Saudi Arabia, 2017-2018. Emerg Infect Dis 2019;25(11):2149-2151

106 Van Kerkhove MD, Alaswad S, Assiri A, et al. Transmissibility of MERS-CoV infection in closed setting, Riyadh, Saudi Arabia, 2015. Emerg Infect Dis 2019;25(10):1802-1809

107 Drosten C, Muth D, Corman VM, et al. An observational, laboratory-based study of outbreaks of Middle East respiratory syndrome coronavirus in Jeddah and Riyadh, kingdom of Saudi Arabia, 2014. Clin Infect Dis 2015;60(03):369-377

108 Memish ZA, Al-Tawfiq JA, Alhakeem RF, et al. Middle East respiratory syndrome coronavirus (MERS-CoV): a cluster analysis with implications for global management of suspected cases. Travel Med Infect Dis 2015;13(04):311-314

109 El Bushra HE, Abdalla MN, Al Arbash H, et al. An outbreak of Middle East respiratory syndrome (MERS) due to coronavirus in Al-Ahssa Region, Saudi Arabia, 2015. East Mediterr Health J 2016;22(07):468-475

110 Balkhy HH, Alenazi TH, Alshamrani MM, et al. Notes from the field: nosocomial outbreak of Middle East respiratory syndrome in a large tertiary care hospital-Riyadh, Saudi Arabia, 2015. MMWR Morb Mortal Wkly Rep 2016;65(06):163-164

111 Balkhy HH, Alenazi TH, Alshamrani MM, et al. Description of a hospital outbreak of Middle East respiratory syndrome in a large tertiary care hospital in Saudi Arabia. Infect Control Hosp Epidemiol 2016;37(10):1147-1155

112 Assiri AM, Biggs HM, Abedi GR, et al. Increase in Middle East respiratory syndrome-coronavirus cases in Saudi Arabia linked to hospital outbreak with continued circulation of recombinant virus, July 1-August 31, 2015. Open Forum Infect Dis 2016;3: ofw165

113 Nazer RI. Outbreak of Middle East respiratory syndrome-coronavirus causes high fatality after cardiac operations. Ann Thorac Surg 2017;104(02):e127-e129

114 Assiri A, Abedi GR, Bin Saeed AA, et al. Multifacility outbreak of Middle East respiratory syndrome in Taif, Saudi Arabia. Emerg Infect Dis 2016;22(01):32-40

115 Hunter JC, Nguyen D, Aden B, et al. Transmission of Middle East respiratory syndrome coronavirus infections in healthcare settings, Abu Dhabi. Emerg Infect Dis 2016;22(04):647-656

116 Cauchemez S, Van Kerkhove MD, Riley S, Donnelly CA, Fraser C, Ferguson NM. Transmission scenarios for Middle East respiratory syndrome coronavirus (MERS-CoV) and how to tell them apart. Euro Surveill 2013;18(24):20503

117 Cauchemez S, Fraser C, Van Kerkhove MD, et al. Middle East respiratory syndrome coronavirus: quantification of the extent of the epidemic, surveillance biases, and transmissibility. Lancet Infect Dis 2014;14(01):50-56

118 Chowell G, Abdirizak F, Lee S, et al. Transmission characteristics of MERS and SARS in the healthcare setting: a comparative study. BMC Med 2015;13:210 
119 Al-Abdallat MM, Payne DC, Alqasrawi S, et al; Jordan MERS-CoV Investigation Team. Hospital-associated outbreak of Middle East respiratory syndrome coronavirus: a serologic, epidemiologic, and clinical description. Clin Infect Dis 2014;59(09):1225-1233

120 Hijawi B, Abdallat M, Sayaydeh A, et al. Novel coronavirus infections in Jordan, April 2012: epidemiological findings from a retrospective investigation. East Mediterr Health J 2013;19(Suppl 1):S12-S18

121 Oboho IK, Tomczyk SM, Al-Asmari AM, et al. 2014 MERS-CoV outbreak in Jeddah-a link to health care facilities. N Engl J Med 2015;372(09):846-854

122 Alraddadi B, Bawareth N, Omar H, et al. Patient characteristics infected with Middle East respiratory syndrome coronavirus infection in a tertiary hospital. Ann Thorac Med 2016;11(02):128-131

123 Almekhlafi GA, Albarrak MM, Mandourah Y, et al. Presentation and outcome of Middle East respiratory syndrome in Saudi intensive care unit patients. Crit Care 2016;20(01):123

$124 \mathrm{Kim}$ YS, Aigerim A, Park U, et al. Sequential emergence and wide spread of neutralization escape Middle East respiratory syndrome coronavirus mutants, South Korea, 2015. Emerg Infect Dis 2019;25(06):1161-1168

125 Al-Tawfiq JA, Auwaerter PG. Healthcare-associated Infections: the hallmark of the Middle East respiratory syndrome coronavirus (MERS-CoV) with review of the literature. J Hosp Infect 2019; 101(01):20-29

126 Alfaraj SH, Al-Tawfiq JA, Altuwaijri TA, Alanazi M, Alzahrani N, Memish ZA. Middle East respiratory syndrome coronavirus transmission among health care workers: implication for infection control. Am J Infect Control 2018;46(02):165-168

127 Kim C-J, Choi WS, Jung Y, et al. Surveillance of the Middle East respiratory syndrome (MERS) coronavirus ( $\mathrm{CoV})$ infection in healthcare workers after contact with confirmed MERS patients: incidence and risk factors of MERS-CoV seropositivity. Clin Microbiol Infect 2016; 22(10):880-886

128 Wiboonchutikul S, Manosuthi W, Sangsajja C. Zero transmission of Middle East respiratory syndrome: lessons learned from Thailand. Clin Infect Dis 2017;64(Suppl 2):S167-S170

129 Hall AJ, Tokars JI, Badreddine SA, et al. Health care worker contact with MERS patient, Saudi Arabia. Emerg Infect Dis 2014;20(12): 2148-2151

130 Kim SG. Healthcare workers infected with Middle East respiratory syndrome coronavirus and infection control. J Korean Med Assoc 2015;58:647-654

131 Alraddadi BM, Al-Salmi HS, Jacobs-Slifka K, et al. Risk factors for Middle East respiratory syndrome coronavirus infection among healthcare personnel. Emerg Infect Dis 2016;22(11):1915-1920

132 Noorwali AA, Turkistani AM, Asiri SI, et al. Descriptive epidemiology and characteristics of confirmed cases of Middle East respiratory syndrome coronavirus infection in the Makkah Region of Saudi Arabia, March to June 2014. Ann Saudi Med 2015;35(03):203-209

133 Zumla A, Azhar EI, Arabi Y, et al. Host-directed therapies for improving poor treatment outcomes associated with the Middle East respiratory syndrome coronavirus infections. Int J Infect Dis 2015;40:71-74

134 Gossner C, Danielson N, Gervelmeyer A, et al. Human-dromedary camel interactions and the risk of acquiring zoonotic Middle East respiratory syndrome coronavirus infection. Zoonoses Public Health 2016;63(01):1-9

135 Kasem S, Qasim I, Al-Doweriej A, et al. The prevalence of Middle East respiratory syndrome coronavirus (MERS-CoV) infection in livestock and temporal relation to locations and seasons. J Infect Public Health 2018;11(06):884-888

136 Aly M, Elrobh M, Alzayer M, Aljuhani S, Balkhy H. Occurrence of the Middle East respiratory syndrome coronavirus (MERS-CoV) across the Gulf Corporation Council countries: four years update. PLoS One 2017;12(10):e0183850
137 Al-Tawfiq JA, Memish ZA. Lack of seasonal variation of Middle East respiratory syndrome coronavirus (MERS-CoV). Travel Med Infect Dis 2019;27:125-126

138 Hart BJ, Dyall J, Postnikova E, et al. Interferon- $\beta$ and mycophenolic acid are potent inhibitors of Middle East respiratory syndrome coronavirus in cell-based assays. J Gen Virol 2014; 95(Pt 3):571-577

139 de Wilde AH, Raj VS, Oudshoorn D, et al. MERS-coronavirus replication induces severe in vitro cytopathology and is strongly inhibited by cyclosporin A or interferon- $\alpha$ treatment. J Gen Virol 2013;94(Pt 8):1749-1760

140 Falzarano D, de Wit E, Martellaro C, Callison J, Munster VJ, Feldmann $H$. Inhibition of novel $\beta$ coronavirus replication by a combination of interferon- $\alpha 2 b$ and ribavirin. Sci Rep 2013; 3:1686

141 Al-Tawfiq JA, Momattin H, Dib J, Memish ZA. Ribavirin and interferon therapy in patients infected with the Middle East respiratory syndrome coronavirus: an observational study. Int J Infect Dis 2014;20:42-46

142 Omrani AS, Saad MM, Baig K, et al. Ribavirin and interferon alfa2a for severe Middle East respiratory syndrome coronavirus infection: a retrospective cohort study. Lancet Infect Dis 2014; 14(11):1090-1095

143 Spanakis N, Tsiodras S, Haagmans BL, et al. Virological and serological analysis of a recent Middle East respiratory syndrome coronavirus infection case on a triple combination antiviral regimen. Int $\mathrm{J}$ Antimicrob Agents 2014;44(06): 528-532

144 Khalid M, Al Rabiah F, Khan B, Al Mobeireek A, Butt TS, Al Mutairy E. Ribavirin and interferon- $\alpha 2 b$ as primary and preventive treatment for Middle East respiratory syndrome coronavirus: a preliminary report of two cases. Antivir Ther 2015;20(01): 87-91

145 Tawalah H, Al-Qabandi S, Sadiq M, Chehadeh C, Al-Hujailan G, AlQaseer M. The most effective therapeutic regimen for patients with severe Middle East respiratory syndrome coronavirus (MERS-CoV) infection. J Infect Dis Ther 2015;03:1-5

146 Al Ghamdi M, Alghamdi KM, Ghandoora Y, et al. Treatment outcomes for patients with Middle Eastern Respiratory Syndrome Coronavirus (MERS $\mathrm{CoV}$ ) infection at a coronavirus referral center in the Kingdom of Saudi Arabia. BMC Infect Dis 2016;16:174

147 Arabi YM, Alothman A, Balkhy HH, et al; And the MIRACLE trial group. Treatment of Middle East respiratory syndrome with a combination of lopinavir-ritonavir and interferon- $\beta 1 \mathrm{~b}$ (MIRACLE trial): study protocol for a randomized controlled trial. Trials 2018;19(01):81

148 Aburizaiza AS, Mattes FM, Azhar EI, et al. Investigation of antimiddle East respiratory syndrome antibodies in blood donors and slaughterhouse workers in Jeddah and Makkah, Saudi Arabia, fall 2012. J Infect Dis 2014;209(02):243-246

149 Gierer S, Hofmann-Winkler H, Albuali WH, et al. Lack of MERS coronavirus neutralizing antibodies in humans, eastern province, Saudi Arabia. Emerg Infect Dis 2013;19(12): 2034-2036

150 Müller MA, Meyer B, Corman VM, et al. Presence of Middle East respiratory syndrome coronavirus antibodies in Saudi Arabia: a nationwide, cross-sectional, serological study. Lancet Infect Dis 2015;15(05):559-564

151 van Doremalen N, Bushmaker T, Munster VJ. Stability of Middle East respiratory syndrome coronavirus (MERS-CoV) under different environmental conditions. Euro Surveill 2013;18(38): 20590

152 Leclercq I, Batéjat C, Burguière AM, Manuguerra JC. Heat inactivation of the Middle East respiratory syndrome coronavirus. Influenza Other Respir Viruses 2014;8(05):585-586 
153 WHO. WHO|Infection prevention and control of epidemic-and pandemic prone acute respiratory infections in health care. WHO2015

154 World Health Organization (WHO). Infection prevention and control of epidemic-and pandemic prone acute respiratory infections in health care. WHO2015

155 CDC. Interim Infection Prevention and Control Recommendations for Hospitalized Patients with Middle East Respiratory Syndrome Coronavirus (MERS-CoV). 2015. Available at: https://www.cdc.gov/coronavirus/mers/infection-prevention-control.html. Accessed March 9, 2017

156 Kandeil A, Gomaa M, Nageh A, et al. Middle East respiratory syndrome coronavirus (MERS-CoV) in dromedary camels in Africa and Middle East. Viruses 2019;11(08):717

157 Ali MA, Shehata MM, Gomaa MR, et al. Systematic, active surveillance for Middle East respiratory syndrome coronavi- rus in camels in Egypt. Emerg Microbes Infect 2017; 6(01):e1

158 Kasem S, Qasim I, Al-Hufofi A, et al. Cross-sectional study of MERS-CoV-specific RNA and antibodies in animals that have had contact with MERS patients in Saudi Arabia. J Infect Public Health 2018;11(03):331-338

159 Chu DK, Poon LL, Gomaa MM, et al. MERS coronaviruses in dromedary camels, Egypt. Emerg Infect Dis 2014;20(06): 1049-1053

160 Farag EA, Haagmans BL, Al-Romaihi H, et al. Failure to detect MERS-CoV RNA in urine of naturally infected dromedary camels. Zoonoses Public Health 2019;66(05):437-438

161 Hui DS, Memish ZA, Zumla A. Severe acute respiratory syndrome versus the Middle East respiratory syndrome. Curr Opin Pulm Med 2014;20:233-241 